\title{
Evaluation of Gifted and Talented Students' Reflective Thinking in Visual Arts Course
}

\author{
Mehmet Ali Genç \\ Division of Art Education, Necmettin Erbakan University, Turkey
}

Copyright $(02016$ by authors, all rights reserved. Authors agree that this article remains permanently open access under the terms of the Creative Commons Attribution License 4.0 International License.

\begin{abstract}
The use of higher order thinking skills is necessary for the education of gifted and talented students in order to ensure that these students, who have development potential compared to their peers, use their capacities at maximum level. This study aims to present gifted and talented students' reflective thinking skills, one of the higher order thinking skills, in visual arts education. The study examines reflective thinking skills of gifted and talented students in a literature-assisted visual arts activity. The study adopts a qualitative approach and quasi-experimental design. The sample of the study consists of 12 students receiving education in the third grade. According to findings of the present study which uses teacher and student interview forms as data collection tools, the study concludes that students have demonstrated reflective thinking skills in the aspects of questioning, reasoning, and evaluation during the activity.
\end{abstract}

Keywords Reflective Thinking, Giftedness, Gifted and Talented Student

\section{Introduction}

Development higher order thinking skills has gained importance in preparing education programs which are intended for cultivating individuals who can keep up with changes of the modern age in which development and evolution are rapid.

Each and every individual and society currently make some decisions about their future behaviors on the basis of their previous actions or by considering repeating the very same ones. This situation appears in the field of education as it does in daily life. This behavior, which is a kind of thinking skill, is named reflective thinking in education and it has developed recently [1].

In his 1910 book, "How We Think?", John Dewey [2] systematizes reflective thinking, defined as the thinking process for solving problems and revealing positive and negative situations in relation to the level of teaching or learning method of the individual [3]. Dewey defines reflective thinking as the kind of thinking that consists in turning a subject over in the mind and giving it serious and consecutive consideration. According to another definition, reflective thinking is the thinking of an individual-at or after the moment of learning- about what and how much s/he has learned on the basis of what $\mathrm{s} / \mathrm{he}$ has just learned and thinking deeply to decide on the new information to be learned by means of self-evaluation [3].

Dewey [2] categorizes school courses under three types of knowledge: Skill Studies (such as reading and writing), Informational Studies (such as geography and history) and Disciplinary or Logical Studies (such as arithmetic). Dewey indicates that informational studies could easily turn into "A cyclopedia of useless information" and emphasizes the importance of students' acquisition of the knowledge on their own. Students' acquisition of knowledge on their own is enabled thanks to reflective thinking skills. Reflective thinking, which consists of argument, problem, hypothesis, reasoning and testing, allows students to think intentionally before and during the lesson, and enables a connection between student's previous learning and newly acquired knowledge [4]. Students under the supervision of a teacher can decide on "how, when and why" they need to learn in reflective thinking, which enables students to think about their learning, to become aware of their learning and to express their opinions about learning [5].

According to Dewey [2], reflective thinking involves (1st phase) a state of doubt, hesitation, perplexity, mental difficulty, in which thinking originates, and (2nd phase) an act of searching, hunting, inquiring to find material that will solve the doubt, settle and dispose of the perplexity. Furthermore, according to Dewey the second phase is composed of the following five aspects: suggestions, an intellectualization of the difficulty or perplexity, the use of one suggestion after another as a leading idea, or hypothesis, testing the hypothesis [2].

The education of gifted and talented students was launched in Turkey in 1993 [6] for the purpose of raising self-awareness of gifted and talented students about their individual skills and using their capacities at maximum level 
[7], and the idea of Science and Art Center was developed and spread in 1996 [8]. These centers provide visual arts education in addition to scientific education. The Directive on Science and Art Centers (Bilsem) regulates that these centers are administered in a manner that students are raised to become individuals who learn through experience, who produce, who solve problems, and who can think creatively, who can communicate with people, who can do scientific research and invent. Furthermore, these centers are tasked with giving due attention to planning and implementing of activities that allow developing metacognitive thinking skills [7]. This study enables students to demonstrate their reflective thinking skills thanks to the activity prepared in line with reflective thinking skill which is one of the higher order skills.

\subsection{The Purpose and Importance of the Study}

Higher order thinking skills take an important place in the education of gifted and talented students. In this activity process, the students are expected to gain experiences which will enable them to improve their reflective thinking skills.

Reflective thinking, which enables effective learning and shows what is happening in the minds of students, aims to present the effect on gifted and talented students in the aspects of questioning, reasoning and evaluation. It is considered that the conclusions of the study would contribute to the education of the gifted and talented in the field of visual arts.

The problem statement of the study is "How is the reflective thinking of students about the visual arts activity prepared?"

Sub-problems are as follows:

1. "How is the reflective thinking of students about the visual arts activity in relation to questioning?"

2. "How is the reflective thinking of students about the visual arts activity in relation to reasoning?"

3. "How is the reflective thinking of students about the visual arts activity in relation to evaluation?"

\section{Method}

The study is conducted using interview method, which is one of the qualitative research methods. Qualitative researches are the ones in which data collection methods such as observation, interview and document analysis are used, perceptions and phenomena are revealed in a realistic and holistic manner in their natural settings and certain content is examined in depth and in detail [9]. Punch [10] regards interviewing as the primary data collection tool and stating that it is a very good way of accessing people's perceptions, interpretations, definitions of situations and constructions of reality.

Study group consists of 5 female and 7 male students, a total of 12 students in the orientation process (the third grade students) in Konya Meram Science and Art Center in
2013-2014 school year.

\subsection{Data Tools}

The activity of "Build a City" was prepared in line with the existing literature. The prepared visual arts activity was shared with students, their opinions on the activity plan were taken into consideration, and the activity was submitted to the field experts for their opinions. Necessary corrections were made in line with comments and suggestions of experts.

The researcher not only played an active role in the course of the process as a direct participant but also assumed an observer identity. The study benefited from the observer teachers in addition to the researcher. For this purpose, three observer teachers who participated in the activity accordingly observed the students.

"Teacher Interview Form" and "Student Interview Form" used by observer teachers were prepared in order to exhibit the contribution of this activity to the reflective thinking skills of the students Teacher and student observation questions were prepared considering that the actions performed in the reflective thinking process focus on three main aspects (questioning, reasoning and evaluation) in the literature review $[2 ; 11]$. There are six open-ended questions in the student interview form regarding what a student does for a better learning and success (Questioning); the role of the student in the activity and the reasons of success (Reasoning); and student's self-evaluation of observation, study, trial and creation (Evaluation). There are six open-ended questions in the teacher interview form regarding the student activity and questioning of their own success (Questioning); the role of the student in the activity and the reasons of success (Reasoning); and the student's self-evaluation of observation, study, trial and creation (Evaluation). "Student Interview Form" and "Teacher Interview Form" which were prepared by the researcher by taking expert opinions were applied during the activity and at the end of activity. Written responses were preferred considering daily work load of teachers and students.

\subsection{Data Analysis and Interpretation}

Descriptive data analysis was used to analyze the responses to teacher and student interviews which were data collection tools. Data obtained from descriptive analysis are typically summarized and interpreted according to pre-determined themes. The purpose of such type of analysis is to present obtained findings to readers in an organized and interpreted manner. Data are summarized and interpreted, and direct quotations are common in the descriptive analysis for the purpose of reflecting the opinions of individuals conspicuously [9].

Teacher and student observations were directly quoted while explaining findings about sub-problems. In the presentation of the findings, the comprehension of the subject was improved by providing quotations that include different, contradictory, negative and positive explanations 
or descriptions. The researcher demonstrated objective attitudes and behaviors in preparing, developing, implementing and analyzing data collection tools of the study.

\subsection{Validity and Reliability of Data}

Data diversification is used for validity and reliability of the study. Diversification is used to obtain data collected for the purpose of the study by different methods, and to test the credibility of the findings of the study [9]. To this end, this study uses two different sources of data, namely teacher interviews and student interviews to confirm the findings and ensure that the data are consistent.

Since the implementer of the activity, who is the researcher himself, has worked in this institution for the last five years, he has spent a long time and interacted with observer teachers and students. This situation helps both ensure participants' rapport in the data collection process and obtain detailed and in-depth data. Interactions of experts experienced in qualitative studies were ensured at all stages of the study. Multiple checks were made for determining the consistency.

\subsection{The Activity of "Build a City"}

By building a cardboard city, the activity targets the reflective thinking skills of students. As preliminary preparation, necessary materials (acrylic or watercolor paint, ruler, tape, styrofoam, drawing paper, scissors, adhesive) and visual arts workshop were prepared.

Students and observer teachers were informed about purpose and phases of the activity one week before the activity. The activity plan was reorganized based on the opinions of the students and the observer teachers. Moreover, students and teachers were informed about reflective thinking skill.

Lesson 1: The class was split up into groups before the lesson for the group study. Three groups including four students were created considering students' preferences while creating groups. Students were asked what they thought about the planning of the city they lived in, and themes of urbanization and urban planning were discussed. Real world examples were given about this issue and students were asked to give examples. It was aimed to ensure that the students had full knowledge of the subject. Attention of students was attracted to the subject by questions such as "What part of your city would you ideally like to live in?", "What part of your city would you like to have your house in?" The responses showed that almost all students preferred central parts of the city.

In the second phase of the activity, students were asked to describe the unfolded version of geometric shapes drawn on the blackboard and they were asked to draw these versions on drawing paper as a one-piece paper (Figure 1). After the completion of drawings, papers were cut and folded. The pieces were glued together with the help of adhesives and shapes were completed. They were asked to answer whether completed geometric shapes resembled architectural structures or not. A flat surface was prepared for the placement of these geometric shapes, and students were asked to build a city by placing geometrically shaped house and building models on the flat surface. It was seen that almost all students placed these houses in the city center randomly. After the placement, the students were asked to answer the question "Would you like to live in a city where buildings are placed disorderly and without any rule?". After receiving answers, questions "What kind of a city would you like to live in?", "What should be done for that purpose?" were asked and the necessity of urban planning was discussed. The following answers were received: there should be avenues, fitness centers, and large parks in the city; the color of the buildings should be in harmony with each other, and housing in historical places should not be allowed. It was stated that city and neighborhood planning was shaped upon aesthetics and this issue concerns everyone. After discussions about urban aesthetics and planning, re-planning of cardboard city was discussed.

For the next lesson, students were asked to do some research about urban planning and each group was asked to plan a cardboard city in the lesson and make a presentation to other groups about it.
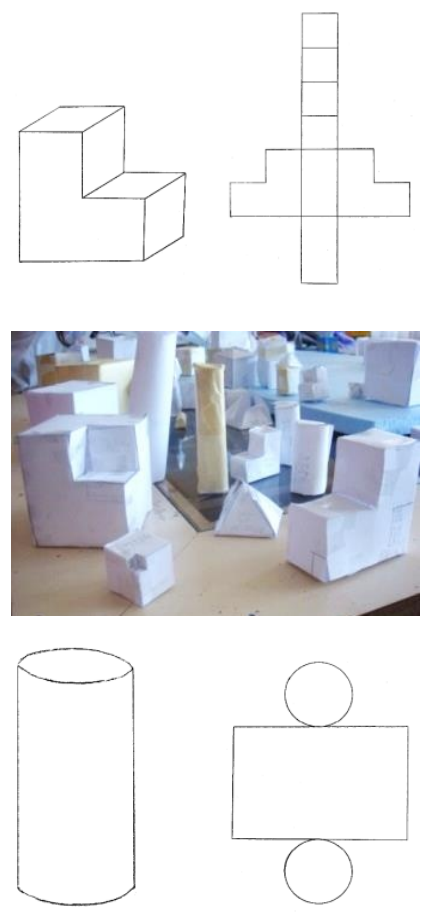

Picture 1. Images from modeling workshop of students

Lesson 2: In the third phase of the activity, students who did some research about urban planning and attended the activity well-prepared were asked to plan a new cardboard city. After students discussed their opinions about urban planning in their study groups, they started to work with great enthusiasm. Groups that completed their urban planning started to place their cardboard cities, glued together the prepared building-shaped figures on the flat 
surface, and then painted them (Picture 2).

In the fourth stage of the activity, each group made a presentation of the city it built to other groups.
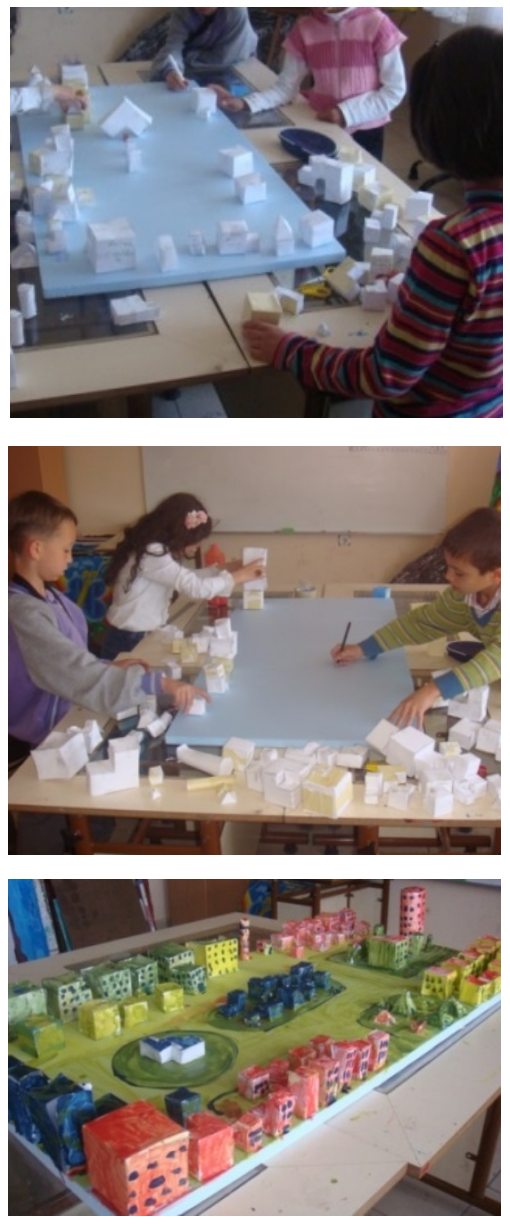

Picture 2. Images from workshop of students

\section{Findings and Interpretation}

\subsection{Findings about the First Sub-Problem and Interpretation}

The following section provides the data, obtained from teacher and student interview forms, regarding the reflective thinking of students about the questioning during the activity.

Students thought reflectively by questioning the activity itself, themselves, their roles in the activity, the teacher, friends and learning environments during the activity.

Given the findings, students' enthusiasm and enjoyment of the activity along with a high interest and participation in activity paved the way for questioning by the students. Some of the quotations from teacher and student interviews regarding student's reflecting thinking skills are as follows:

"We were excited to start the activity, we were able to ask any question we wanted and we discussed them. We succeeded in the activity." (S.11).
"Friends who previously did not use to attend the lesson and would not even raise hand are working for their tasks now... They ask questions to the teacher about the activity. Encouraged by their motivation, I studied better." (S.2).

"I was happy to observe that the students enjoyed and liked to ask questions, and that they felt comfortable. We institutionally aim to raise the children as individuals who question" (T.2).

"I think it is very good that s/he can compare the old cities with the new ones in urban planning and make questioning and comments like 'the cities were in touch with nature'." (T.1).

"Since children took pleasure in the activity, they could look at the activity with questioning minds." (T.3).

"...Like all my friends, I liked this lesson, I wish it could always be like this... We were more successful because of the competition. We did our best." (S.3).

It was observed during the activity that group work brought success and the students reminded their friends, who had not done their tasks, to fulfill their responsibilities after distribution of tasks. Relevant quotations are below:

"We succeeded because we completed the subjects that we had been lacking by helping each other. I was scared that we would be unsuccessful when we did not work together with my friends. The cardboard city and presentation were successful since we worked together." (S.7).

"I observed that children liked question-answer method; the students questioned group formation and success of their friends and themselves. The students studied jovially as if they were playing in the park. They also ensured the participation of their friends." (T.1).

"I was also very pleased to work in a group; we warned friends who did not work in the group. For example, a friend did not cooperate while we were working. We persuaded her/him otherwise our group would fail." (S.6).

"When we asked some friends to work or wondered why they did not work, they were offended. But we made it up. We took part in the same group." (S.9).

The researcher briefed the students and the observer teachers about the phases of the activity one week in advance so that the students were prepared for the activity and knew what they would do. Students came prepared for the activity and they were excited to start as soon as possible. This ensured that the students became aware of and questioning about the subjects they were going to learn about. Ünver [3] points out those questions asked by teachers to students, by students to teachers and by students to students influence the development of reflective thinking.

"Since students attended the class by making preliminary preparation for the activity on their own, their interest and participation in the activity were 
good. Instead of accepting everything as given, they questioned." (T.3).

"Sharing the objectives with students in advance and questioning nature of the activity enabled the students to be active and enthusiastic in every phase of the activity." (T.1).

"When I attend the class prepared knowing what I will learn about, I want to learn more and I constantly ask myself whether I have reached my goal or not." (S.5.).

"When the groups were set, we eagerly divided the work among ourselves. Everything was easier when we knew what we would do. We discussed the subjects within the group. We discussed pros and cons of the suggestions made by our friends." (S.4).

Implementation of group work in the activity created a friendly competition among students. Reminding each other to do their tasks ensured questioning. Relevant quotations are below:

"I worked with my friend in the activity thanks to the group work. My friend helped me learn something that I previously had not understood. We warned our friend who did not do his/her task." (S.1).

"Implementation of the group work in the lesson created a friendly competition among students and ensured that students communicated with each other more easily. Communication led to success." (T.1).

"A student asked why they could not choose all of the group friends after admitting that the teacher listened to them during the formation of groups. The question of the student shows that s/he is questioning." (T.2).

An opinion of a student, who states that the only negative aspect of the activity was duration, is as follows:

"We planned a very beautiful city; however, the time was insufficient...then, we created an easier cardboard work. But two friends did not like this..." (S.11).

Students learned by associating their own experiences with the new ones. The process of activity allowed experiences activating students. In the activity, opinions that associating former knowledge with the new information by students leads to success are as follows:

"When I asked students why they did this in their work, they answered 'We did this to let the air in the city. My father previously worked in Urfa where houses are built with backyards for ensuring that houses are spacious; therefore, it was observed that students considered environment and climate conditions in their designs and made use of their visual experiences from places they visited." (T.1).

"I always wanted to have seats in front of our library. We did this in this cardboard city. Our teacher also liked it." (S.4).

"I observed that students associated their knowledge with the new information and made reason-oriented questioning, they made observation and planning, and that they did their share of the task." (T.2).

"The question and answer section showed that the urban design of two students was influenced by climate and geographical conditions, that they were taught such information in a Geography course. Another student stated that s/he watched it in a documentary that narrates the shape of houses were particularly affected by the climate. Accordingly, these show that the students use their previous knowledge in this lesson and they are successful." (T.1).

"Students associate the information they learn with their daily life. Therefore, students become a part of this activity." (T.3).

The activity closely associated with daily life attracted the attention of students, and ensured that students studied better, asked questions and learned more. The researcher established a connection between the activity with the life by presenting examples from everyday life. The researcher asked the students to give examples and they contributed to the activity with their examples. Relevant quotations are below:

"The researcher ensured that the activity was in connection with our daily life by presenting examples from daily life, thereby augmented the success of the activity."(T.1).

"The teacher gave examples about the city which we lived in. Then, we gave examples from our surroundings, especially from our neighborhood." (S.9).

"I think examples from daily life are very important to leave a lasting impression on the students. I think students will remember this lesson when they see non-planned urban housing and narrow streets." (T.4).

"The importance of urban planning in life was discussed. The subject was entirely within life... I think the activity also makes a major contribution to teachers." (T.1).

"While researcher was giving examples to students from daily life about narrow streets, a student said 'Narrow street is good for the sincerity of neighbors... our previous house was on a narrow street, I could see my friends even when I stared out of the window', this expression of the student indicates that s/he is questioning." (T.3).

Opinions indicating that students were questioning, that they asked questions to the researcher about the subject and they enjoyed doing that, and that the researcher encouraged the students to take part in the activity by asking new questions, that the students were comfortable while asking questions and expressed themselves easily, are as follows:

"If students ask questions and give answers to questions comfortably, there is an unconstrained 
environment. Then, they express their ideas easily. Thus, the work of the researcher is facilitated, and questioning of students ensures that they learn on their own and they conduct their own researches better." (T.3).

"Sometimes I come up with an idea and then I join. Everyone expresses opinions. Some friends say incorrect things and teacher corrects them at that time." (S.2).

"By giving students an opportunity to express themselves in the activity, the researcher ensured that they were aware of what they felt and learned, and that they, therefore, thought reflectively." (T.2).

"I enjoy the class discussions. The subject is diversified. Creative ideas rise, some ideas surprise us. Then, we think about interesting examples. Some friends make jokes.” (S.6).

"In order to increase participation in the discussion, the researcher ensured that students were included in the activity by asking new questions. S/he ensured the questioning was performed and that interesting things were part of the discussion." (T.1).

"Our teacher encourages us to ask questions. We understand whether we learn or not. If a friend does not learn, we help him/her." (S.11).

The students made efforts to be successful and discussed with their friends during the activity. It was observed that students, when challenged, consulted with the researcher, their best performing friends, and people who were interested in the subject. Relevant quotations are below:

"I observed that the students exerted every effort for success and tried to do their best in the activity, they discussed with their friends even during the breaks and they were questioning; therefore, they used reflective thinking skills." (T.1).

"It was seen that the students consulted with the teachers for the subjects they had difficulty in understanding, in addition, they received help from friends who were successful in the activity and consulted with group friends." (T.2).

"I ask my friends who were more successful than I am about how they work. Recently, our teacher gave a task to a friend, and s/he completed with the help of a relative. I consult with the subject matter teachers about the subjects I do not understand" (S.7).

Student discussion on the subject matter and efforts to perform better created a noisy environment. The researcher did not intervene in order not to discourage the students. Opinions of students and teachers on this issue are as follows:

"The students started to express themselves more comfortably and they study more eagerly, even those students who did not attend the class regularly normally started to take an active role in the group work. On purpose, the researcher did not intervene when the environment became noisy." (T.1).

"I enjoyed the activity. Different ideas come up, we make noise since we are surprised by some ideas and make jokes, and sometimes we discuss. But, we warn each other without the warning of the teacher." (T.2).

\subsection{Findings about the Second Sub-Problem and Interpretation}

The following section provides the data, obtained from teacher and student interview forms, regarding the reflective thinking of students about the reasoning during the activity.

The researcher allowed the students to talk, discuss, share their ideas freely, study on their own, and develop new ideas and suggestions by preparing a comfortable educational environment for the activity. Therefore, the researcher prepared the ground for reflective thinking of students. The literature points out that enabling the development of reflective thinking skills in the learning environments may enhance the learning quality of students [12].

The students' thinking about their learning in every phase of the activity and raising awareness of their roles and the reasons of their successes and failures in the activity show that they think reflectively. Relevant quotations are below:

"The researcher offered a learning environment in which students can talk and discuss with friends, share their ideas freely and feel comfortable during the learning process." (T.1).

"My role in the activity was to make a research on urban planning and I did it. I considered myself successful as I fulfilled my responsibility." (S.10).

"We distributed the work among friends. Our group was good. Our friends worked, too. We owe our success to our sharing of the work." (S.11).

"I observed in the activity that the researcher made an effort to contribute to the development of reflective thinking skills of the students by satisfying their needs and interests." (T.3).

"I do not want to talk when I come to class unprepared; nothing comes to my mind and I cannot give an answer when the teacher asks something. However, I prepared like my friends and participated in the activity." (S.5). "My friends accuse me when I do not do my task. Fortunately, I completed the planning task that they could not do. My father is an architect, I consulted with him." (S.7).

In the course of activity, the researcher tried to increase motivations of students by guiding the students and asking questions to them. Relevant quotations are below:

"The researcher guided the work of the students by prompt questions during the activity process. Speeches that enhance the motivation provided efficient participation of students in the activity..." (T.2).

"Our teacher guided us, I consulted with my friends 
who were good at colors, and then it turned into something very beautiful. If I had not consulted, I would have failed." (S.8).

Self-questioning of the students and planning for their own work indicates that they think reflectively. Quotations are below:

"That the students created the cardboard city in line with a plan while building it, and that they painted after gluing together the cardboard and then started to prepare their presentations show that the students were following a planned work" (T.2).

"The following expression by a student 'I always wanted to have benches/seats in front of library for resting. We did this in my cardboard city' shows s/he does planning for his/her work." (T.1).

The students thinking about their work consulted with friends in the same group and with the researcher for doing better. Furthermore, they made preparation, distributed tasks and did good planning for success. Relevant quotations from students are below:

"We made preparation for learning the subject better. However, we consulted with the teacher and with successful friends because we could not sufficiently come together with group friends." (S.9).

"Although our product was not good, we were successful in doing the research. We brought together the researches that we made on the subject of urban planning, selected good ones, consulted with the teacher and gave a task to a friend who was good at computer. S/he prepared a good presentation." (S.7).

"We were not good at the outset; the reason was that we did not distribute the work well. But, we consulted with our competent friends in the second phase of the activity. We did good planning and succeeded..." (S.8).

That the students participated in the activity with preparation and studied the subject matter by cooperation among themselves; and that they had preliminary information about the activity and exerted necessary effort ensured the success of the activity. Relevant quotations are below:

"I observed that students studied cooperating among themselves and everyone did their own part." (T.1).

"My group friends tried to do their best. Some of them made efforts on the cardboard while others made the research. The outcome was good." (S.4).

"One of the reasons of the success is to maintain harmony within study groups created during activity process. Since students are organized well, the level of success increases" (T.2).

"That these children use knowledge and experiences they gained in the past; that they set objectives, express themselves, ask questions and make predictions increase their success. I believe the students have developed their reflective thinking skill." (T.1).

That the students studied from different resources; and that they made preparations in advance of the activity and asked questions themselves during the activity are among the reasons for success. Relevant quotations are below:

\begin{abstract}
"Students said that they studied from different resources, asked themselves questions and compared their successes with the other groups." (T.3).

"I made preparation and prepared necessary materials before coming to the activity. When I went home, I made preparation for our next study." (S.4).

"During the lesson, I asked myself questions to learn the lesson better and thought about the planning of neighborhood where I lived in. I compared it with the cardboard city we built." (S.4).
\end{abstract}

In the activity, two students thought that participation in this activity was not good; because one student had problem with his friends and the other felt left out of the group:

"...I felt a little left out of my group since my friends were very good at their work. I kept up with them later." (S.7).

"The activity was difficult but sometimes I had problems with my friends..." (S.12).

\subsection{Findings about the Third Sub-Problem and Interpretation}

The following section provides the data, obtained from teacher and student interview forms, regarding the reflective thinking of students about the self-evaluation during the activity.

In the activity, the students were observed to make evaluations about subjects such as attending class with preparation, knowing about the content of the lesson, planning their work, making observations and trials and creating a product; and therefore to perform reflective thinking skill. Dolapçıŏlu [5] indicates that self-evaluation and questioning assist student's communication, planning, organization and reflection of self-learning.

The students worked freely and took responsibility in the activity. They had the opportunity to self-evaluate about their successes and failures by facing them. Saygilı and Atahan [13] point out that process-related evaluations are made by foreseeing unexpected situations in reflective thinking which requires being aware of what is done, why it is done and how expected results are achieved. Relevant quotations are below:

"We helped each other; we found friends who were good at doing it and assigned them tasks; I am not good at creating a cardboard and gluing the parts of it. For this reason, I prepared group presentation. Sometimes I helped friends. But things did not work out as we wished. Other groups outperformed us. I 
wish we could work again ..." (S.10).

"Even the students who hated homework were happy to be assigned with a home assignment on research in preparation for the next lesson by the researcher. Such statements by the students as 'We should study better', 'My uncle is an architect, I can consult him about it' when they saw the works of other groups indicate that the students self-evaluated." (T.1).

"That a student tells another student 'Actually I could have done my work better if we got on well with group friends...' during a break shows that the student makes an evaluation about the activity." (T.3).

"If I had an opportunity of making urban planning one more time, I would plan the city more orderly. I can do better if I work." (S.1).

"After the observation of the activity, reflecting thinking attracted my attention even more. I think this activity is very beneficial not only for students but also for teachers." (T.3).

Student's evaluation of his/her work and awareness of his/her success not only allow the student to do better but also help him/her find a field of interest and work in that field. Dolapçıŏlu [5] remarks that a self-questioning student can determine his/her field of interest by means of reflecting his/her own actions. Relevant quotations are below:

"I found this activity quite important as it allows the students to realize their interests and talents, to use their talents more frequently, and to realize their strengths and weaknesses." (T.2).

"I was happy when the teacher made the lesson entertaining and I worked harder. I was pleased to be praised when my teachers and friends liked the cardboard city and painting of it that I made. I felt talented in the field of painting..." (S.9).

The students performed reflective thinking skill by self-evaluating their learning and friends' learning, and making evaluations about what they would do in case of failure. Gelter [14] states that we perform reflective thinking skills on our own when something goes wrong, when we are afraid of failure or when we face a crisis in real life. Reflective skill, which requires an individual to see himself/herself from outside as an objective observer, involves critical analysis of actions in line with educational targets of the individual [15]. Relevant quotations are below:

"At the outset, we fell behind the other groups. We re-distributed the tasks. It was better. My cutting and painting work were praised. Our friend prepared a good presentation..." (S.9).

"I observed that students took decisions in their study groups, distributed tasks and evaluated themselves and group friends about the work." (T.1).

"My participation in the activity was not very good. Because I could not make the cardboard houses very well, I said to myself that I could do better, and my friends helped me do." (S.12).

"I was afraid that I would fail in the group study at the beginning of the activity. But, we fulfilled our tasks and warned friends who did not fulfill theirs" (S.1).

It was also observed that the sense of responsibility was acquired and the students whose senses of responsibility were underdeveloped were warned, and that internal control mechanism in the group was developed in the activities. Relevant quotations are below:

"Although it was exhausting, I want lessons to be taught in this manner; because we had a group task. When a group friend did not work, we were all affected. For this reason, we did our share of the task in the group." (S.2).

"Group discussions allowed students to discuss both the researcher and with the group friends and to evaluate themselves. Furthermore, they reminded each other of their tasks." (T.3).

Guidance of the students by the teacher in the process of activity; absence of an intervening attitude by the teacher towards the works produced; permission of the teacher to the students find their own solutions and attention to student preferences prepared the ground for self-evolution of the students. Relevant quotations are below:

"Our teacher did not intervene in our work. We studied from the available books and on the internet and received help from the father of a friend. Everyone applied his/her idea together with the group. We studied before teacher told us to do so." (S.5).

"We did not even want to have a break during this activity. We wanted to complete our activity-related work as we competed with other groups; our teacher did not intervene even when we fell behind and left the outcome to us." (S.4).

"Non-intervention by the researcher in the work of the students and plain guidance by the researcher enabled the students to self-evaluate." (T.3).

"I understood the importance of reflective thinking after the activity, it will be beneficial if I use it in my classes; however, I think I need some space and time to make meeting of the possible. If there were not these deficiencies, the activity would be more successful." (T.1).

Although the activity was very well enjoyed, the insufficiency of time and physical environment, the presence of a few students who did not fulfill their shares of the distributed task, and the noise resulting from the exchange of information during the activity were echoed by the students as follows:

"There was enough time, indeed. I could not use time efficiently because of my friend; s/he did not do his share of the task and did not cooperate. Although the teacher liked them all, I think we could have been more successful." (S.8). 
"My biggest problem was the time. I thought that I would not be able to complete the subject within given time. This situation prevented me from working harder." (S.10).

\section{Conclusions and Recommendations}

According to findings of the study, the activity ensured that students exhibited positive performance in terms of questioning, reasoning, and evaluation, and that they performed reflective thinking skills.

Opinions of the teachers and of the students about the activity were positive in general. Interest and curiosity of students were aroused in the activity and student participation in the in-class discussion was ensured. An appropriate environment for the development of thinking in the activity was prepared; ideas of the students were included in the activity, and an activity that would activate reflective thinking skills of the students was planned. A class environment where students expressed themselves comfortably was created by asking them open-ended questions during the activity. It was ensured that students thought about alternative methods and point of views by establishing a connection between the subject matter with real life.

Conclusion on the first sub-problem: The students thought reflectively in the activity by questioning themselves, the teachers, their friends, and their learning environment.

The students' enthusiasm and enjoyment of the activity along with a high interest and participation in activity paved the way for questioning by the students. Students knew in advance what they were going to do during the activity and came prepared for the activity. This ensured that the students were aware of and questioning the subjects they were going to learn about. The students striving for success became questioning by associating their own experiences with the new ones, asking questions to the researcher about the subject matter, and consulting with the researcher, group friends and relevant people about the subjects they had difficulty in understanding.

Conclusion on the second sub-problem: The students' thinking about their learning in every phase of the activity and raising awareness of their roles and the reasons of their successes and failures in the activity show that they think reflectively.

That the students participated in the activity with preparation, studied the subject matter by cooperation among themselves; and that they had prior knowledge about the activity and studied from different resources and questioned themselves during the activity and made planning about the work they would do are considered as the reasoning for success.

Conclusion on the third sub-problem: The students performed reflective thinking by making evaluations about subjects such as attending class with preparation, knowing about the content of the lesson, making planning about their works, making observations and trials, and creating a product. The students performed reflective thinking skills by making evaluations about their own learning, learning from their friends, taking responsibility for their work, facing their successes and failures, and guidance of the researcher.

Insufficient time and physical environment, along with the noise resulting from the exchange of information in the activity were reflected as negative aspects of the activity.

The activity which enabled reflective thinking in the sense that it determines imperfect and incorrect learning of students not only allowed the students to evaluate themselves but also allowed the teacher to evaluate both himself/herself and learning of his/her students. Through this activity, Reflective thinking has been appropriate enough for orientation training of the Science and Art Centers (Bilsem), it is recommended to be implemented in the entire Science and Art Centers orientation process.

Time insufficiency for students and spatial insufficiency for group work were experienced in the activity. It is recommended to create more leisure time during which students can study, and to allocate spaces apart from classes for groups or individual studies in the Science and Art Centers so that the activities could enable reflective thinking become more successful.

It is recommended to conduct activity planning so as to provide development of reflective thinking in all phases of education since the inclusion of educational environments, which unveils students' learning and their ways of learning, in the teaching plans lays the ground for reflective thinking of students.

\section{REFERENCES}

[1] Z. Y1ld1z, Reflective thinking in religious teaching, Ankara, Pegem Academy, 2016.

[2] J. Dewey. How we think; a restatement of the relation of reflective thinking to the educative process, New York, D. C. Heath and Company, 1933.

[3] G. Ünver, Reflective thinking, Ankara, Pegem A Publications, 2003.

[4] D. Kirnık. Effect of reflective thinking developing activities on student achievement in grade 5 Turkish courses of elementary education, unpublished master thesis, Firat University, Institute of Social Sciences, Department of Elementary Education, Discipline of Classroom Teaching, Elâzığ, 2010.

[5] S. D. Dolapçığlu. Assessment of reflective thinking levels of classroom teachers, unpublished master thesis, Mustafa Kemal University, Institute of Social Sciences Department of Elementary Education, Hatay, 2007.

[6] N. Dönmez. Regulations required for the establishment and functioning of science and art centers, in A. Kulaksızoğlu, A. E. Bilgili, M. R. Şirin (Ed.), I. Gifted Children Congress in Turkey, İstanbul, Children Foundation Publications, 69-84, 2004. 
[7] Bilsem Directive. (Science and Art Centre Directive), Republic of Turkey, Ministry of National Education, Ankara, 2015.

[8] F. Akarsu. The gifted. in M. R. Şirin, A. Kulaksızoğlu \& A. E. Bilgili, (Ed.), Selected Articles Book for Gifted Children, Istanbul, Children Foundation Publications, 127-154, 2004.

[9] A. Yıldırım \& H. Şimşek, Qualitative research methods in social sciences (Edition II), Ankara, Seçkin Publications, 2000.

[10] K. F. Punch, Introduction to social surveys, in D. Bayrak, H. B. Arslan, \& Z. Akyüz (Trans.), Ankara, Siyasal Kitabevi, 2005.

[11] A. Baki, F. Aydın Güç, \& Z. M. Özmen. The ınvestigation of pre-service mathematic teachers' reflective thinking skills toward problem solving, International Journal of Curriculum and Instructional Studies, Vol.2, No.3, 59-72, 2012.
[12] F. Bayrak. Effect of blog application of reflective thinking skill, unpublished master thesis, Hacettepe University, Institute of Sciences, Ankara, 2010.

[13] G. Saygilı \& R. Atahan. Examination of gifted children's reflective thinking skills towards problem solving in terms of several variations, Süleyman Demirel University Faculty of Arts and Sciences Journal of Social Sciences, Vol.31, 181-192, 2014.

[14] H. Gelter. Why is reflective thinking uncommon? Reflective practice, Vol.4, No.3, 337-344, 2003.

[15] F. Bölükbaş, Impact of reflective teaching on attitudes and achievements of primary education secondary stage students towards Turkish Course, unpublished doctoral dissertation, Dokuz Eylül University, Institute of Educational Sciences, İzmir, 2004. 